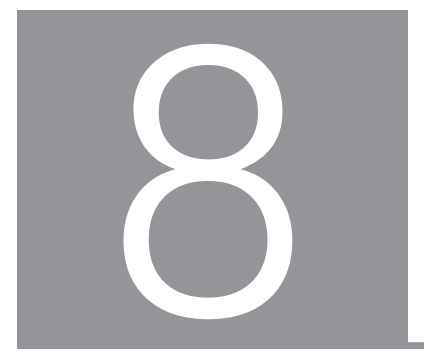

\title{
ENABLING CONSTRUCTIVE \\ ENGAGEMENT THROUGH \\ KNOWLEDGE OF THE \\ NON-PROFIT SECTOR'
}

\section{Deidré van Rooyen \& Willem Ellis}

\section{ABSTRACT}

The third sector plays a vital role in service delivery within communities. In the Free State this sector is largely disempowered and the applied research on this sector is minimal. Any party wanting to interact with non-profit organisations must have an informed understanding of the third sector. By means of telephonic interviews, focus group sessions and face-to-face interviews with provincial government officials and non-profit organisations in Mangaung and Matjhabeng, this research provides insight into co-creating developmental solutions for challenges in South Africa through knowledge enablement in collaboration with higher education. It elaborates on the background of the state and format of the third sector in the province of the Free State, reviewing issues such as non-profit governance, staffing, sources of income and income-generating activities.

1 Information gathered and reproduced in this chapter partially stems from a research project conducted by the Centre for Development Support (CDS) for the International Labour Organization (ILO) culminating in a publication entitled "The potential of non-profit organisations in the Free State Province to adopt a social enterprise approach". The report was published under the auspices of the SME Observatory of South Africa. 


\section{INTRODUCTION}

The cliché "to know me is to love me" is in all probability not applicable to the third sector in South Africa, but does contain a kernel of truth in that the higher education sector needs to know those with whom they interact in order to increase the possibility of a mutually satisfactory relationship. Since the South African third sector plays a crucial role in addressing the needs of vulnerable groups in society, and in helping government deliver appropriate services, any party wanting to reciprocally interact with it must have a well-rounded knowledge and understanding of this sector in all its permutations. For higher education institutions (HEls) engaging with this sector, through the avenues of teaching, research and community engagement (including service learning), this is even truer.

The scope of the third sector, especially service rendering non-profit organisations (NPOs), is often greatly underestimated. The Deputy Director of the NPO Directorate states: "Stable community organisations have been found to increase efficient service delivery as well as improve market performance and economic growth" (RSA PCAS 2003:27). According to the Department of Social Development (RSA DoSD 2009), the NPO sector in South Africa was worth R14 billion in 2000. The Department of Social Development (RSA DoSD 201 la) noted that at that stage there were 76175 NPOs listed in the national database. The majority (34\%) of sectors in which NPOs work are classified as social services, with development and housing the second largest focus (21\%). With reference to the Johns Hopkins Comparative Non-profit Sector Study (cited in Salamon, Anheier, List, Toepler \& Sokolowski 1999), Swilling and Russell (2002:16) note that the non-profit sector employed 645316 full-time workers (of which about $50 \%$ are volunteers). Total employment in the non-profit sector in 1999 exceeded the number of employees in many major economic sectors; therefore, this sector forms a fertile area for cooperation and reciprocal partnerships for HEls or any other role-players involved in rendering social services.

Even though the third sector in South Africa has been extensively researched and commented upon in general (RSA DoSD 2011 a; Nzimakwe 2008; Swilling \& Russell 2002; Taylor 2010), the same cannot be said of all provinces. Anecdotal evidence suggests that the NPO environment is, to some degree, disempowered and most NPOs are struggling for financial sustainability and are threatened by ongoing funding cuts from both the state and their traditional donors (Ellis 2013). The dearth of applied research regarding the third sector makes it problematic for any stakeholders, especially HEls wishing to enter into partnerships with it, to do so.

This chapter thus aims to paint a picture of the third sector and its numerous contributions, using a snapshot of the Free State third sector environment as a 


\section{ENABLING CONSTRUCTIVE ENGAGEMENT THROUGH KNOWLEDGE OF THE NON-PROFIT SECTOR}

case in point. We argue that knowledge of the third sector provides insight into its role in co-creating developmental solutions for challenges in South Africa through knowledge enablement with higher education. In this chapter we therefore attempt to elucidate these aspects of the provincial third sector, reviewing issues such as third sector governance, staffing, sources of income and income-generating activities. We conclude by reflecting on the $\mathrm{HEI}$ engagement that the research was based on - being a contract research assignment undertaken by the Centre for Development Support (CDS) on request of the International Labour Organization (ILO). The role that CDS played in this engagement is also briefly considered.

\section{BACKGROUND ON NON-PROFIT ORGANISATIONS IN SOUTH AFRICA}

Maximising the delivery of developmental social services to the people of South Africa is a process that requires an interrelated, intersectoral and integrated service delivery model. This process demands participation, cooperation and the strengthening of good working relations and partnerships with many sectors, such as all three spheres of government, NPOs, civil society in general and the private sector (RSA DoSD $2011 \mathrm{c}: 29$ ). NPOs have played and continue to play a significant role in providing social services and addressing social problems in South Africa (Conradie 1999:291). Currently, there are approximately 30000 various categories of social service professionals servicing the population of 50.17 million (RSA DoSD $2011 \mathrm{c}: 11$ ). The partnership between the government and NPOs can be described as a relationship rooted in the acceptance by both parties of their shared vision, principles and responsibilities for the delivery of services within the accepted policy framework. The Departments of Social Development and Health provide the public with a call for service plans and undersign a memorandum of understanding with each of the organisations for the funding that they receive to render welfare services to the population. In these service agreements the organisations agree to provide each such department with progress reports (including statistics) of their activities for monitoring and evaluation purposes. This process has elicited various challenges and therefore in Chapter 5 (Social development) of the Provincial budget expenditure review 2005/06-2011/12 (RSA National Treasury 2009) the National Treasury highlighted the need for the social development sector to strengthen its partnership with the NPOs through the review of the Policy on financial awards to service providers and the development of the financing arrangements.

Registered NPOs are classified in terms of the nature or scope of their services or the sectors in which they operate. Table 8.1 indicates the number of NPOs operating in different sectors in South Africa and in the nine provinces. This information is also available for the Mangaung and Matihabeng municipalities in the Free State because the study further deals with these areas. 


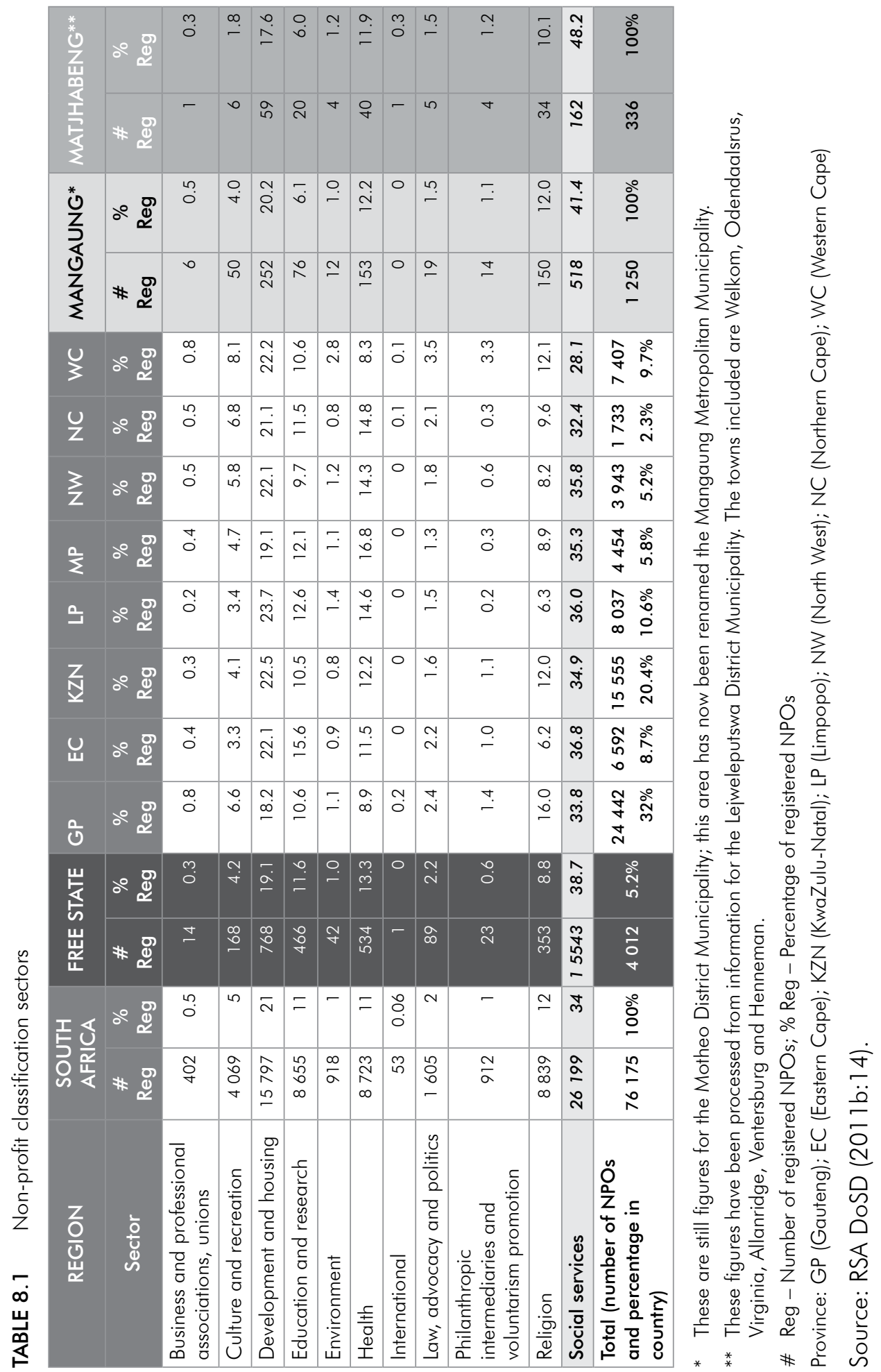


As has been mentioned before, the Department of Social Development (RSA DoSD 2011 a) noted that there were 76175 NPOs listed on the national database in 2000. Of these, 95\% were voluntary associations, 3\% were section 21 companies (non-profit companies under the New Companies Act 71 of 2008) (RSA 2008), and $2 \%$ were trusts (these types are also discussed later in the chapter). The majority (34\%) of sectors in which NPOs work are classified as social services. Development and housing is the second largest focus with $21 \%$ of NPOs involved nationally. Registered NPOs in the Free State contribute to 5.2\% (4 012) of the total registered NPOs in the country, which makes it the province with the third lowest (after North West and the Northern Cape) number of registered NPOs (RSA DoSD 2011 b:2).

Furthermore, in the Free State more than 45\% of NPOs work in social services, and $98 \%$ of NPOs are registered as voluntary organisations. This means that those supporting the development objectives of such an organisation should have the opportunity to join in its activities as partners in development (Nzimakwe 2008:91). Trusts make up $1 \%$ of this total, while section 21 companies comprise only $1 \%$ (RSA DoSD 2011 b).

Table 8.1 indicates that the percentage of registered NPOs in each sector is very similar for all the provinces. However, the Free State Province stands out with the highest percentage (38.7\%) of NPOs in the social services sector. This percentage is even higher in Mangaung (41.4\%) and Matjhabeng (48.2\%).

\section{SNAPSHOT OF NON-PROFIT ORGANISATIONS IN THE FREE STATE}

In order to obtain an overview of the NPO environment in the Free State, the CDS2 developed a two-page questionnaire and conducted interviews with NPOs that work in the Free State. The data collected relate to the number, type and size of active NPOs; the employment levels/number of jobs in the NPO sector (formal and informal jobs) disaggregated by gender and by sub-sector/type of services being provided by an NPO; the services provided by NPOs and their clients' contractual basis; and the existing income/revenue sources of NPOs. The contact information of these NPOs was obtained from various sources like the GreaterCapital network of NPOs (such as Tshikululu Social Investments and GivenGain), the Free State Consultative Welfare Forum and Sangonet. It cannot be guaranteed to represent an accurate replica of the non-profit sector in the Free State, but at least it provides a

2 CDS is a development studies research and teaching centre within the Faculty of Economic and Management Sciences at the University of the Free State (UFS) with the aim of promoting sustainable human development in the Southern African society broadly and in central South Africa in particular. 
good picture of the environment and creates a snapshot of the composition of the sector and the issues with which it struggles.

Telephonic structured interviews were conducted with 115 organisations of which almost 65\% were in Mangaung, 11\% in Matihabeng, 13\% not physically based in the Free State but doing work in the Free State, and the other $11 \%$ in other parts of the Free State. Only three (2.6\%) of the NPOs interviewed were not registered. Surprisingly, $65.2 \%$ of these NPOs were also registered in terms of section 18A of the Income Tax Act 58 of 1962. Acquiring the status of a public-benefit organisation (PBO) is a difficult task, given that this act does not define with any certainty what it means by 'public benefit'. This lack of definition leaves the onus on the NPO to prove that its work provides a public benefit, with many NPOs not having the time and energy to engage in this effort - often leading to the NPO not optimising the benefits to be derived from applicable tax legislation.

Table 8.1 also indicates that the percentage of NPOs registered in the Free State in each sector is similar to that in Mangaung, but the percentage of NPOs working in the social service sector is even higher than in the Free State as a whole (almost $39 \%$ in the Free State and $41 \%$ in Mangaung). Furthermore, the Department of Social Development (RSA DoSD $2011 \mathrm{~b}$ ) notes that the trend concerning the total number of registered NPOs is consistent with that of the total number of applications received from the districts within the Free State. The Motheo District Municipality $\left(\mathrm{DC} 17^{3}\right.$ ) had the highest number of registered NPOs at $31 \%$, followed by Thabo Mofutsanyane (DC19) at 26\% and Lejweleputswa (DC18) at 20\%. Xhariep (DC16) had the lowest number of registered organisations at $8 \%$ and was surpassed by Fezile Dabi (DC20) at 16\%.

\subsection{Types of services}

Table 8.2 illustrates the distribution of the NPOs interviewed according to the type of service rendered.

TABLE 8.2 Types of services rendered by NPOs in the Free State

\begin{tabular}{|l|c|c|}
\hline Services & Number of NPOs & Percentage (\%) \\
\hline HIV/Aids & 20 & 17.4 \\
\hline Education and training & 15 & 13.0 \\
\hline Youth development & 9 & 7.8 \\
\hline Community development & 8 & 7.0 \\
\hline Mental health and education & 7 & 6.1 \\
\hline
\end{tabular}

3 DC = district code 
ENABLING CONSTRUCTIVE ENGAGEMENT THROUGH KNOWLEDGE OF THE NON-PROFIT SECTOR

\begin{tabular}{|l|c|c|}
\hline Services & Number of NPOs & Percentage (\%) \\
\hline Community-based care and support (frail care) & 7 & 6.1 \\
\hline Children's homes and places of safety & 6 & 5.2 \\
\hline Social welfare services (child) & 5 & 4.3 \\
\hline Social welfare services (general) & 5 & 4.3 \\
\hline Social welfare services (disability) & 4 & 3.5 \\
\hline Victim empowerment and counselling & 4 & 3.5 \\
\hline Social welfare services (aged) & 3 & 2.6 \\
\hline Family support & 3 & 2.6 \\
\hline Environmental (animals/wildlife) & 3 & 2.6 \\
\hline Drug abuse and prevention & 2 & 1.7 \\
\hline Other & 2 & 1.7 \\
\hline Total & 115 & $100 \%$ \\
\hline
\end{tabular}

Similar to the pattern in South Africa, the registered NPOs working in social welfare services $(20.8 \%=$ total percentage of sectors shaded in grey in Table 8.2$)$ outnumber the other sectors. Some of the organisations also covered various services. The majority of beneficiaries of these NPOs were children (26.5\%), the youth (16.9\%), the aged (14.7\%) and people with disabilities (14.4\%).

\subsection{Management/governance structures and staff}

Table 8.3 shows the number of members in the governance structures in the various categories as well as the staff in each of the type of employment opportunities that NPOs offer. The table indicates the minimum, maximum and average number indicated by the NPOs interviewed.

TABLE 8.3 Management/governance and staff of NPOs in the Free State

\begin{tabular}{|l|c|c|c|}
\hline \multicolumn{1}{|c|}{ Governance/management structure } & Minimum & Maximum & Average \\
\hline Total governance/management structure & 1 & 17 & 7 \\
\hline Number of members of the board - external & 1 & 9 & 5 \\
\hline Number of members of the board - internal & 1 & 16 & 5 \\
\hline Number of members of the board - males & 1 & 9 & 4 \\
\hline Number of members of the board - females & 1 & 13 & 4 \\
\hline \multicolumn{1}{|c|}{ Staff } & Minimum & Maximum & Average \\
\hline Total number of staff & 1 & 150 & 20.74 \\
\hline Number of staff - male & 1 & 35 & 4.26 \\
\hline Number of staff - female & 1 & 115 & 14.51 \\
\hline Total number of staff - administrative/technical staff & 1 & 10 & 2.50 \\
\hline Total number of staff - project manager/coordinator & & & 2.25 \\
\hline
\end{tabular}




\begin{tabular}{|l|c|c|c|}
\hline \multicolumn{1}{|c|}{ Staff } & Minimum & Maximum & Average \\
\hline Total number of staff - social workers & 1 & 12 & 2.67 \\
\hline Total number of staff - health professionals & 1 & 15 & 4.56 \\
\hline Total number of staff - auxiliary workers & 1 & 9 & 2.65 \\
\hline Total number of staff - care workers & 1 & 42 & 11.27 \\
\hline Total number of staff - volunteers & 1 & 100 & 19.60 \\
\hline Total number of staff - trainees & 3 & 5 & 4.00 \\
\hline $\begin{array}{l}\text { Total number of staff - other skilled workers } \\
\text { (teachers, councillors) }\end{array}$ & 1 & 30 & 5.00 \\
\hline Total number of staff - drivers & 1 & 4 & 1.50 \\
\hline $\begin{array}{l}\text { Total number of staff - other unskilled workers } \\
\text { (gardeners, cleaners, cooks) }\end{array}$ & & 4 & 1.50 \\
\hline
\end{tabular}

From Table 8.3 it is clear that the non-profit sector employs many people at various levels, from unskilled workers to professionals such as social workers and project managers. At each of these levels, the number of employees differs drastically among the organisations, but when one looks at the averages, the numbers start telling the true story. The members of boards are almost equally divided between external (4.62) and internal (4.75) members and between females (4.38) and males (3.60). The number of staff also shows that more females (an average of 16.35 per organisation) are employed in the non-profit sector. It should be noted that this sector also depends heavily on volunteers (an average of 19.60 per organisation).

\subsection{CHALLENGES}

According to Nzimakwe (2008:90), globalisation has brought so many unexpected changes to the functioning of governments that NPOs now provide many of the services which governments are sometimes unable to fulfil. South African NPOs have done sterling work in improving the lives of ordinary citizens, according to President Jacob Zuma at the National NPO Summit in Johannesburg in August 2012. Zuma stated that the non-profit sector should remain an indispensable partner to government as it pursues the development agenda (Khumalo 2012).

It is a well-known fact that the non-profit sector faces specific (sectoral) challenges, and this often comes across in the media and is mentioned during everyday conversations. The main issues that emerged from the research can be summarised in the following points (often utilising the exact utterances of the contributors).

\subsubsection{Lack of coordination and concerted effort}

The services available in the Free State are not equally spread across the province. In large parts of the rural Free State there are no local organisations which can 
be contacted for services. Even though the Free State is small and there are fewer NPOs, the organisations do not network among themselves because, according to the participants, they are all "fighting for a piece of the same small cake" 4 (for financial means as well as beneficiaries they serve). Clients also play off organisations against one another for their own institutional gain. It is therefore suggested that the NPOs should start collaborating and working together to improve the lives of all the beneficiaries and to make their work easier.

Integration and coordination between different government departments are often lacking. According to government officials "double-dipping" becomes a problem where money is wasted, because various government departments are covering similar targets (like the Department of Social Development and the Department of Agriculture assisting the same project).

There is a lack of transparency between the government and NPOs. Consistency in terms of parameters (for example, how many staff members per beneficiary) is needed. It is difficult to build relationships between public officials and NPOs because of the turnover rate of staff.

\subsubsection{Lack of good governance and management}

Governance and management structures are often not in place, or the importance of sound governance is underestimated or misunderstood. There tends to be a lack of management skills within the organisations as well as within the relevant government departments.

NPO staff members have not been trained for the skills that are needed in these financially difficult times. In many cases, they are not sufficiently business-oriented. Reporting is often a problem, with NPO management lacking the necessary skills or with the reporting process remaining inconsistent.

According to the participants in the study, people working with and for NPOs are often "narrow minded" in their views of the potential that their important work holds in terms of assisting the sustainability of their organisations. Because the non-profit sector has been "blessed with the mentality of charity work" by the community as well as employees, the organisations are prepared to perform work as "cheap labour". For NPOs adopting an entrepreneurial approach to the rendering of services could have a number of important implications for their structure and governance, relating,

4 All the words in double quotation marks and italics are an exact transcription of what was reported by the participants (either during interviews or focus-group sessions). The participants' utterances and comments form part of the text so that the context can be reflected. These comments do not reflect the opinions of the research team. 
for example, to their public-benefit status. In the cases where NPOs decide to set up a trading entity, the responsibilities and financial liabilities of managers and board members will change. There generally is insufficient awareness and information around this matter within the NPO community.

\subsubsection{Lack of resources}

Organisations do not always have enough human and physical resources to be able to cover the demands (statutory services ${ }^{5}$ ) of the community and therefore case loads are excessive, with cases not attended to as effectively as necessary. There seems to be a perception among the public that NPOs should be providing these services instead of the government, but the NPOs are merely complementary to the work of the government in delivering the services, and their resources are insufficient to cover all of the population in need.

As a matter of caution, it must be made clear that not all aspects of NPO activities could and should become business-oriented. NPOs depend heavily on volunteers, and their contributions cannot always be seen simplistically. The value of volunteerism should be respected and valued as a social good that has its place in building and strengthening communities. According to one of the NPO managers "in the white community, the volunteers are aged and cannot always cover all aspects of what the organisation depends on. On the other hand, in the black community, there are younger volunteers who are actually looking for jobs". They want to provide a service but are discouraged when there are no stipends for the purposes of their own survival. Well-trained volunteers are often lost when they find employment that puts food on their family's table. NPOs also report a trend where government employs NPO workers or volunteers because of their relevant work experience.

\subsubsection{Financial constraints}

Financial management is critical to the economic sustainability of an NPO (Pajas \& Vilain 2004:342), and the current reduction in available funding has highlighted the importance of financial management for the sustainability of NPOs in a difficult economic environment (York 2009:1). Financial management is one of the most challenging areas that managers of NPOs have to deal with. The greatest challenge experienced by most of the NPOs is financial constraints and that is why, according to the participants of the study, NPOs "come and go". The funding received, mostly from the Department of Social Development, is never enough and is normally between $40 \%$ and $50 \%$ of their income. NPO managers who were part of the focus

5 Services that have to be provided (by law) to communities, such as social welfare (services to children, the aged, the disabled and the frail). 
group furthermore noted that not all organisations disclose all their means of income for the fear that "the subsidy will be decreased".

There is an ongoing critique that salaries are low in NGOs and that benefits are not always in place. In other words, NPOs constitute a 'decent work deficit' (Webster et al 2008). This is the case because they often do not have the funding in place to offer higher salaries - either on a project basis or for the 'core' tasks of the NPO and then use casual or subcontracted workers or even volunteers. The government's subsidy cycle is also only issued on an annual basis, and therefore continuity, sustainability and planning for the NPOs are difficult. The working conditions also contribute to problems with the retention of staff. In the NPO environment employees are often forced into difficult conditions and are overworked. Funding and donations are not always consistent. If this financial support is withdrawn, the organisations that do not have reserves in place may not be able to continue. This also cause NPO employees (at all levels) to leave NPOs in search of better remunerated positions in the public or private sector.

NPO participants commented that many of the NPOs are trying all they can to obtain some money. This means that they are often "selling their souls" and deviating from their mission to be able to access certain grants or funding in order to survive. According to Boschee (1998:2) "social entrepreneurs are non-profit executives who pay increasing attention to market forces without losing sight of their underlying missions, to somehow balance moral imperatives and the profit motives - and that balancing act is the heart and soul of the movement".

The Department of Social Development has not been able to monitor and evaluate the funded organisations consistently. They have also not valued the importance of follow-up visits to the small organisations in order to establish whether they are still on the right track in terms of financial and organisational management. Furthermore, no exit strategy for sustainable livelihood projects ${ }^{6}$ in particular has been established. According to government officials this has in some cases led to the establishment of a state of dependency where funding continues endlessly, and NPOs struggle to continue once the project has been completed. However, this is not always the case as services are often delivered to communities by an NPO in cases where the state is unable to provide it themselves. In this way, the state can outsource some services knowing that NPOs are closer to the target population and are providing a service

6 Core principles underlying sustainable livelihood approaches are that poverty-focused development activities should be people-centred, responsive and participatory, as well as multilevel, conducted in partnership, sustainable and dynamic (Ashley \& Carney 1999:7). 
that needs essential resources that only the state can provide. In this case the NPO should be accountable and prove their worth to the state.

\subsubsection{Sources of income}

Just like any business, NPOs often have to obtain income from various sources to survive. Organisations can no longer depend only on grants and funding from a single source because of the inconsistency of funding cycles, the availability of funding from different sources and the struggle for limited resources. In the Free State the Department of Social Development is the largest source of funding for NPOs. Their total approved payments to a total of 1683 organisations/programmes for 2012/13 was almost R325 000 000. The Thabo Mofutsanyane district received the highest percentage (26.3\%) of the allocation, followed by the Motheo district $(23.5 \%)$ and the Lejweleputswa district (18.7\%). Many of the organisations also obtain funding from the provincial office and not from their districts. The majority of the programmes funded in this way $(9.2 \%$ of the $12.5 \%$ ) are also situated in the Motheo and Lejweleputswa districts. Therefore the bulk of the funding (51.4\%) from the Department of Social Development is distributed in these two districts.

During the snapshot of NPOs in the Free State, organisations were asked to indicate from which sources they received the bulk of their income. Table 8.4 illustrates this breakdown.

TABLE 8.4 Percentage breakdown of NPO income

\begin{tabular}{|l|c|}
\multicolumn{1}{|c|}{ Source } & Percentage (\%) \\
\hline Government subsidy & $40-50$ \\
\hline Proposals and grants & $30-40$ \\
\hline Religious organisations & $20-30$ \\
\hline National Lottery & $20-30$ \\
\hline Fundraising & $10-20$ \\
\hline Income-generating projects & $10-20$ \\
\hline
\end{tabular}

Most of the NPOs indicated that their income was obtained from donations, from government funding by the Departments of Social Development and Health, and from the National Lottery (see Table 8.4). The organisations also specified that other sources of income included international funding, national federations, religious institutions and their own fundraising. During the focus group sessions this issue was further discussed in terms of a percentage breakdown of an organisation's income. This figure varies among the organisations. Certain NPOs (that deliver statutory services, for example) are very reliant on the funding from government (80-100\%) and others (working with HIV and Aids orphans) obtain international funding or 


\section{ENABLING CONSTRUCTIVE ENGAGEMENT THROUGH KNOWLEDGE OF THE NON-PROFIT SECTOR}

donations (90\%). There are particular types of organisations (religious and small) that have to generate all of their income themselves. The percentage breakdown of income is generally discussed in the following section.

\subsubsection{Income-generating activities}

The need for NPOs in the Free State to increase their income-generating activities came across as essential during the scan. Officials from the Department of Social Development noted: "This is what we want ...", "... the [NPOs] should become more sustainable ..." and "... not depend on our funding". NPO participants, on the other hand, stated their position on the matter as follows: "The need for our services from the community is increasing, and the funding opportunities and government money is depleting" and "[t] he belt is tightening and our organisation needs to stop acting like a charity but more like a Donald Trump [business]". Participants concluded that NPOs "need a mind shift". Often the NPOs do things for free, but communities that can afford it are usually willing to pay for services (such as health care, therapy, counselling, training and background knowledge).

During the overview of the NPOs the organisations had to give their opinion on generating their own income. Sometimes two or three ideas were shared. These opinions (as per the words used during the interviews) are summarised in Table 8.5.

TABLE 8.5 Opinions on generating own income

\begin{tabular}{|l|c|}
\hline \multicolumn{1}{|c|}{ Opinion } & Percentage (\%) \\
\hline It is challenging and hard work. & 52.1 \\
\hline Teaches us independence to become sustainable and a necessity. & 17.9 \\
\hline It is easy because it is part of everyday work/get money from public. & 13.2 \\
\hline Funding proposals not extensive enough and therefore not accepted. ${ }^{*}$ & 8.4 \\
\hline Not enough human resources to do social service and raise funds. & 5.3 \\
\hline Generate no income - need help from government. & 3.2 \\
\hline Total & $100 \%$ \\
\hline
\end{tabular}

* This is seen as part of income that is NOT obtained from the government. It is hard work to put together funding proposals

Table 8.5 represents the opinions acquired from the NPOs on income-generating activities. The message is strong that it is a challenging aspect $(52.1 \%)$, but that in this way NPOs can become more sustainable and independent (almost 18\% shared this view). There are several obstacles to overcome, such as proposal writing $(8.4 \%)$ and human resources (5.3\%), but there are organisations that are already entering into this mode (13.2\%). Yet some NPOs still depend on government funding (3.2\%). This dependence is due to the fact that certain welfare services are not 
necessarily designed to generate income, and some NPOs would rather concentrate on providing services for the beneficiaries that they already serve and not venture into other avenues of generating income (see Chapter 11 in this regard).

While income generation and sustainability have become the latest buzzwords in non-profit circles, it is clear that some NPOs are more willing and able to become more self-sustainable than others, because of the effort that this takes at the beginning of an endeavour. Successful income-generating activities are usually run or closely advised by entrepreneurially minded individuals implementing fully fledged business models to provide solutions to pressing social challenges. In this context traditional NPOs that provide much needed, welfare-type services to the most vulnerable in society do not consider making a profit to be part of their business, nor do they have the skills to apply market-based principles to running their organisations.

While the socio-economic challenges in South Africa (seemingly even more concentrated in the Free State) continue to exist, the pool of funds available for NPOs is shrinking, and the competition for those funds is increasing (RSA DoSD $2011 \mathrm{c}$ : 15).

\section{CONCLUSION}

The NPO sector plays a crucial role in the community. In the Free State this sector is largely disempowered and the applied research in this sector is minimal. Therefore this chapter endeavoured to paint a picture of the third sector and its numerous contributions, using a snapshot of the Free State non-profit environment as a case in point. The research completed thus contributes to enabling constructive engagement and co-creation of developmental solutions with this sector. Such engagements can now be founded upon a firmer knowledge base and a clearer understanding of the sector, its makeup and dynamics. Primary among those wishing to partner with the third sector are HEls who will continue to do so using various forms of engagement - ultimately attempting to benefit both the higher education institution and the third sector.

The Centre for Development Support (CDS), as a research unit in the field of human development, often engages in research endeavours aimed at informing and capacitating decision makers and policy formulators. The research done on request of the International Labour Organization (ILO) in this instance is one such example and necessitates a concise reflection on the background of the collaboration between the CDS and the ILO in this regard. The study was undertaken against the background of an emerging partnership between the UFS, the ILO and the Free State Department of Economic Development, Tourism, and Environmental Affairs (DETEA) - concretised in a project entitled the Small and Medium Enterprise 


\section{ENABLING CONSTRUCTIVE ENGAGEMENT THROUGH KNOWLEDGE OF THE NON-PROFIT SECTOR}

Observatory of South Africa. The aim of the Observatory is, among other things, to collate research for the purpose of information-based decision making by policy formulators in relevant Free State provincial government departments in their effort to optimise service delivery, both to the citizens of the province and to the $\mathrm{NPOs}^{7}$ involved. It is against this background that the CDS as a department in a higher education institution endeavours to ensure the strengthening of various actors in the field of human development through knowledge enablement - in this instance having governmental decision makers and policy formulators as initial benefactors, with the NPO environment and citizens supported by improved policies and service delivery stemming from improved governmental approaches.

7 These services include funding as well as support with registration and empowerment programmes

\section{REFERENCES}

Ashley C \& Carney D. 1999. Sustainable livelihoods: Lessons from early experience. London: Department for International Development (DFID). [Retrieved 17 March 2014] http://www. livelihoods.org/info/docs/nrcadc.pdf

Boschee J. 1998. Merging mission and money: A board member's guide to social entrepreneurship. Washington DC: National Centre for Non-profit Boards.

Conradie H. 1999. Non-governmental organisations and financial sustainability. Development South Africa, 16(2):291-297.

Ellis WF. 2013. Chairperson of the board of trustees of Lebone Village and NPO governance consultant. Personal interview on experience in consultancy with the third sector. Bloemfontein.

Khumalo G. 2012. Social Development: 'Sterling work' by SA non-profit sector. South Africa-Info, 17 August 2012. [Retrieved 11 March 2014] http://www.southafrica.info/ about/social/npo-summit-170812.htm

Nzimakwe TI. 2008. South Africa's NGOs and the quest for development. International NGO Journal, 3(5):90-097.

Pajas P \& Vilain M. 2004. Finance of non-profit organizations. In: A Zimmer \& E Priller (eds). Future of civil society: Making Central European nonprofit organizations work. Weisbaden: Springer VS. 341-366.

RSA. 2008. New Companies Act 71 of 2008. Pretoria: Government Printer.

RSA DoSD (Republic of South Africa. Department of Social Development). 2009. Developing good governance practices within the South African NPO sector: Benchmark study reportChapter Two. Pretoria: RSA DoSD. [Retrieved 11 March 2014] http://www.dsd.gov.za/npo/ index2.php? option $=$ com_docman\&task $=$ doc_view\&gid $=68 \&$ ltemid $=39$ 
RSA DoSD (Republic of South Africa. Department of Social Development). 2011 a. 2010/201 1 State of South African registered nonprofit organisations issued in terms of the Nonprofit Organisations Act 71 of 1997. A report from the National NPO Database, April 2011. [Retrieved 12 March 2014] http://www.dsd.gov.za/npo/index2.php?option=com_ docman\&task $=$ doc_view\&gid $=73 \&$ ltemid $=39$

RSA DoSD (Republic of South Africa. Department of Social Development). 2011 b. 2010/201 1 State of Free State registered nonprofit organisations issued in terms of the Nonprofit Organisations Act 71 of 1997. A report from the National NPO Database. Free State Province, June 2011 . [Retrieved 12 March 2014] http://www.dsd.gov.za/npo/index2. php?option $=$ com_docman\&task $=$ doc_view\&gid $=91 \&$ ltemid $=39$

RSA DoSD (Republic of South Africa. Department of Social Development). 2011 c. Policy on financial awards to service providers. [Retrieved 12 March 2014] http://www.dsd.gov.za/ dmdocuments/Policy_on_financial_awards_to_service_providers.pdf

RSA. National Treasury. 2009. Provincial budgets and expenditure review 2005/06 - 2011/12. Chapter 5, Social Development. Pretoria: National Treasury. 67-88.

RSA PCAS (Republic of South Africa. Policy Co-ordination and Advisory Services) 2003. Towards a ten year review: Synthesis report on implementation of government programme. Discussion Document. The Presidency, Pretoria: Government Communication (GCIS).

Salamon LM, Anheier HK, List R, Toepler S \& Sokolowski SW. 1999. Global civil society: Dimensions of the nonprofit sector. The Johns Hopkins Center for Civil Society Studies. [Retrieved 12 March 2014] http://ccss.jhu.edu/wp-content/uploads/downloads/201 1/08/ Global-Civil-Society-I.pdf

Swilling M \& Russell B. 2002. The size and scope of the non-profit sector in South Africa. Pietermaritzburg: Centre for Civil Society, University of Natal.

Taylor R. 2010. Moving beyond empirical theory. In: R Taylor (ed). Third sector research. New York: Springer. 1-10.

Webster E, Benya A, Dilata X, Joynt K, Ngope K \& Tsoeu M. 2008. Making visible the invisible: Confronting South Africa's decent work deficit. Research report prepared for the Department of Labour by the Sociology of Work Unit, University of the Witwatersrand, Johannesburg. [Retrieved 28 February 2014] http://www.labour.gov.za/DOL/downloads/ documents/research-documents/webster.pdf

York P. 2009. The sustainability formula: How non-profit organizations can thrive in the emerging economy. New York: TCC Group. 